\title{
Carcinoma Expleomorphic Adenoma of the Submandibular Gland
}

\author{
Sudhir M Naik, Ashok M Shenoy, Purshottam Chavan, Rajshekar Halkud, Siddharth Biswas \\ Mahesh Kalloli, Sumit Gupta, Akshay Kudpaje
}

\begin{abstract}
Background and objectives: Carcinoma expleomorphic adenoma (CXPA) is a rare neoplasm of the salivary gland which arises in the epithelial component of a pleomorphic adenoma. It is not automatically a high-grade tumor as is traditionally suggested and should be further qualified as to type, grade of carcinoma and extent, since intracapsular and minimally invasive tumors behave favorably.
\end{abstract}

Setting: Department of Head and Neck oncosurgery, Kidwai Memorial Institute of Oncology, Bengaluru.

Case report: A 38-year-old female was referred to our outpatient clinic with history of a painless swelling in the left side of the neck since 8 years. Fine needle aspiration revealed carcinoma of the submandibular gland. Contrast enhanced CT revealed a large heterogeneously enhancing mass lesion in the submandibular fossa with the gland not seen separately. Lymph nodes in level Ib and II were enlarged. Excision of the tumor revealed CXPA with foci of high grade mucoepidermoid carcinoma.

Conclusion: CXPA should no longer be considered a specific diagnosis but a category in which the carcinoma should be typed, graded and quantitated to impart more prognostically and therapeutically relevant data for efficient management.

Keywords: Pleomorphic adenoma, Carcinoma expleomorphic adenoma, Submandibular gland, Mucoepidermoid carcinoma.

How to cite this article: Naik SM, Shenoy AM, Chavan $P$, Halkud R, Biswas S, Kalloli M, Gupta S, kudpaje A. Carcinoma Expleomorphic Adenoma of the Submandibular Gland. J Postgrad Med Edu Res 2013;47(3):162-166.

Source of support: Nil

Conflict of interest: None declared

\section{INTRODUCTION}

Carcinoma expleomorphic adenoma (CXPA) is a rare neoplasm of the salivary gland which arises in the epithelial component of a pleomorphic adenoma. ${ }^{1}$ Carcinomas of the salivary gland comprise only about 3 to $5 \%$ of all head and neck cancers, but comprise of at least 24 different types as documented by WHO due to its diversity. ${ }^{2}$ The management of these malignancies provide a significant challenge to the head and neck oncosurgeons because of their low incidence and their unpredictable long-term outcome. ${ }^{3}$ Clinically meaningful classification of these tumors are needed taking into account both the clinical and pathological parameters for better understanding of the prognosis and treatment. ${ }^{4}$
An extensive literature search of many retrospective studies indicates that histologic tumor grade ranks highly among the most important predictors of outcome for salivary gland carcinomas. ${ }^{5}$ A 5 years survival rate of 85 to $90 \%$ is seen in low and intermediate grade carcinomas while it is only $40 \%$ in high grade carcinomas. ${ }^{3,5}$ Multivariate analysis done on a commendable series studies remarked histologic grade as an independent predictor of outcome and also correlate with other factors like the tumor size and the nodal status. ${ }^{6}$

Here we report, a case of CXPA arising from a long standing case pleomorphic adenoma of parotid of the submandibular salivary gland.

\section{CASE REPORT}

A 38-year-old female was referred to our outpatient clinic with history of a painless swelling in the left side of the neck since 8 years. She noticed a increase in size for the past 5 months. The mass was firm to hard in consistency and measured $5 \times 6 \mathrm{~cm}$ in dimension (Fig. 1). The skin over the swelling had no signs of inflammation. No neck nodes enlargement was seen. Oropharyngeal and laryngeal examination revealed no significant findings. Fine needle aspiration revealed carcinoma of the submandibular gland. Contrast enhanced computed tomography (CT) revealed a large heterogeneously enhancing mass lesion in the submandibular fossa with the gland not seen separately. Lymph nodes in level Ib and II were enlarged (Figs 2 and 3). A provisional diagnosis of a malignant tumor of the submandibular gland was done.

Under general anesthesia submandibular gland excision with supraomohyoid neck dissection was done. Subplatysmal flap was raised by a left-sided cervical collar incision. The mass was excised in total and level I, II and III were removed. The lingual, hypoglossal, spinal accessory and greater auricular nerves were identified and preserved (Fig. 4).

Histopathology revealed carcinoma expleomorphic adenoma of the submandibular gland invading more than $1.5 \mathrm{~cm}$ into the adjacent fibrocollageneous tissue (Fig. 5). The malignant component is predominantly undifferentiated carcinoma with foci of high-grade mucoepidermoid carcinoma (Figs 6 and 7). A single node in level I showed a 

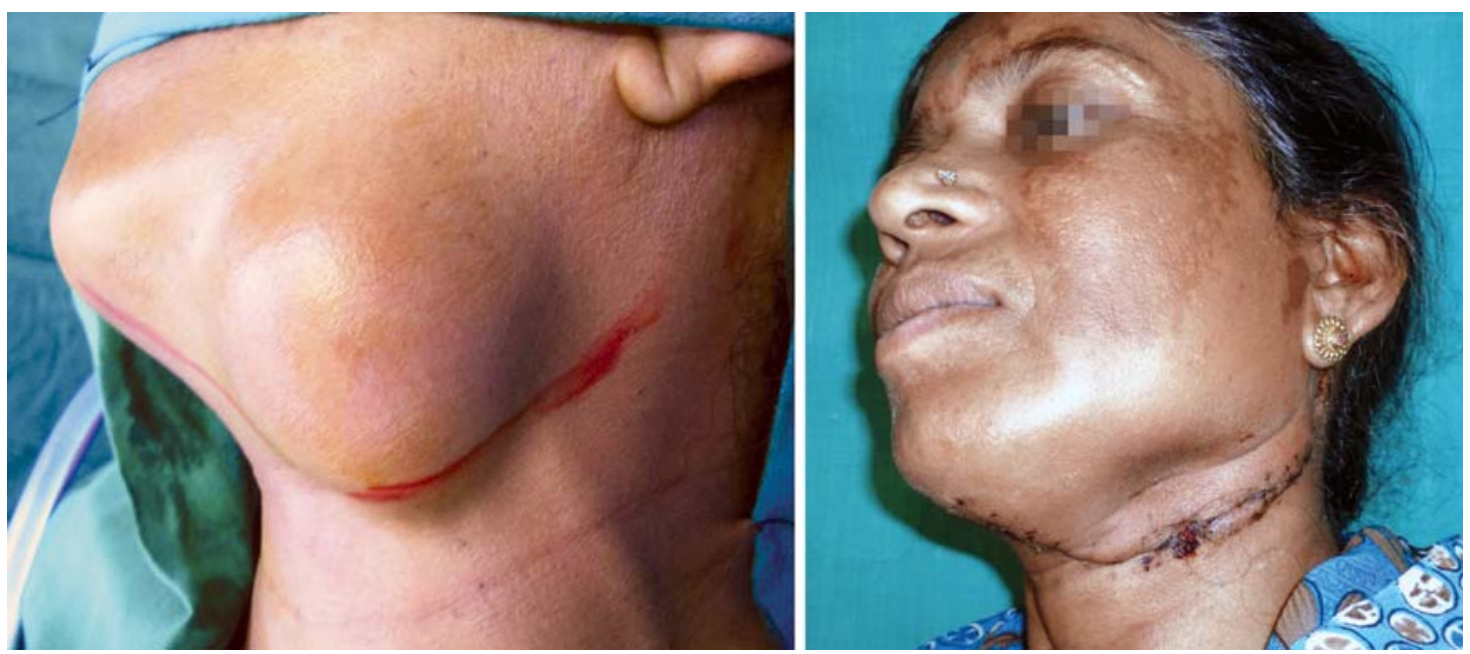

Fig. 1: Pre- and postoperative views of the submandibular gland swelling

reactive changes while 25 nodes in level II and III also showed reactive changes.

\section{DISCUSSION}

CXPA is a rare, highly malignant tumor and comprise of 3.6 to $11.7 \%$ of all salivary gland malignancies. ${ }^{7,8}$ It usually develops from malignant transformation of a longstanding pleomorphic adenoma of major salivary glands., ${ }^{7,8}$

CXPA is usually a more poorly circumscribed mass than the benign pleomorphic adenoma and usually occurs in men
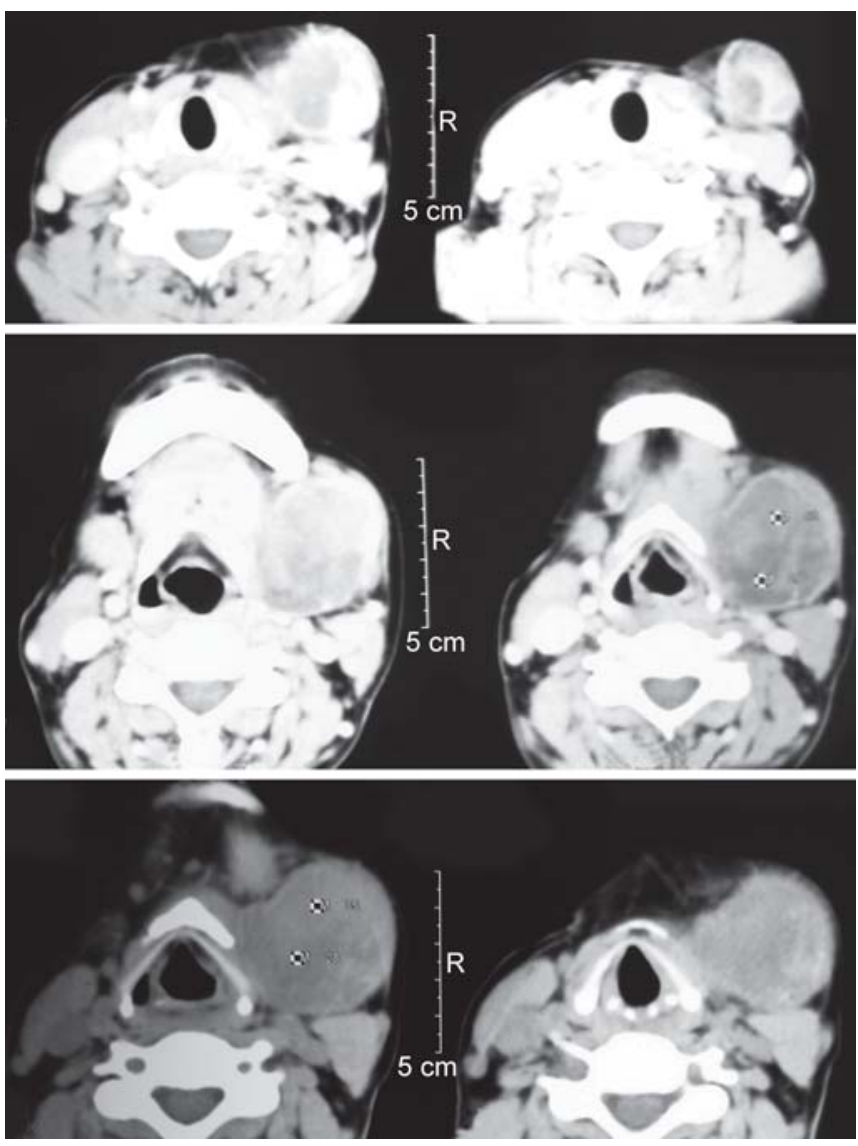

Fig. 2: Axial cuts showing heterogeneous mass with no separation from the submandibular gland in six decade of life. ${ }^{9}$ They are prone for frequent recurrence and commonly metastatize and are seen in major salivary gland in $80 \%$ of cases and minor in $20 \%$ of the cases. ${ }^{10,11}$ In the major salivary glands parotid amounts to $81.7 \%$ of cases, submandibular $18 \%$ and sublingual $0.3 \%$ of the cases. ${ }^{12}$

Incidences in males are three times more than in females and are rarely seen in cases less than 20 years. ${ }^{13,14}$ Clinically present as a mass of long standing duration with a sudden increase in size. ${ }^{13,14}$ Clinical features of pain, facial nerve palsy and fixation to surrounding soft tissues are seen in
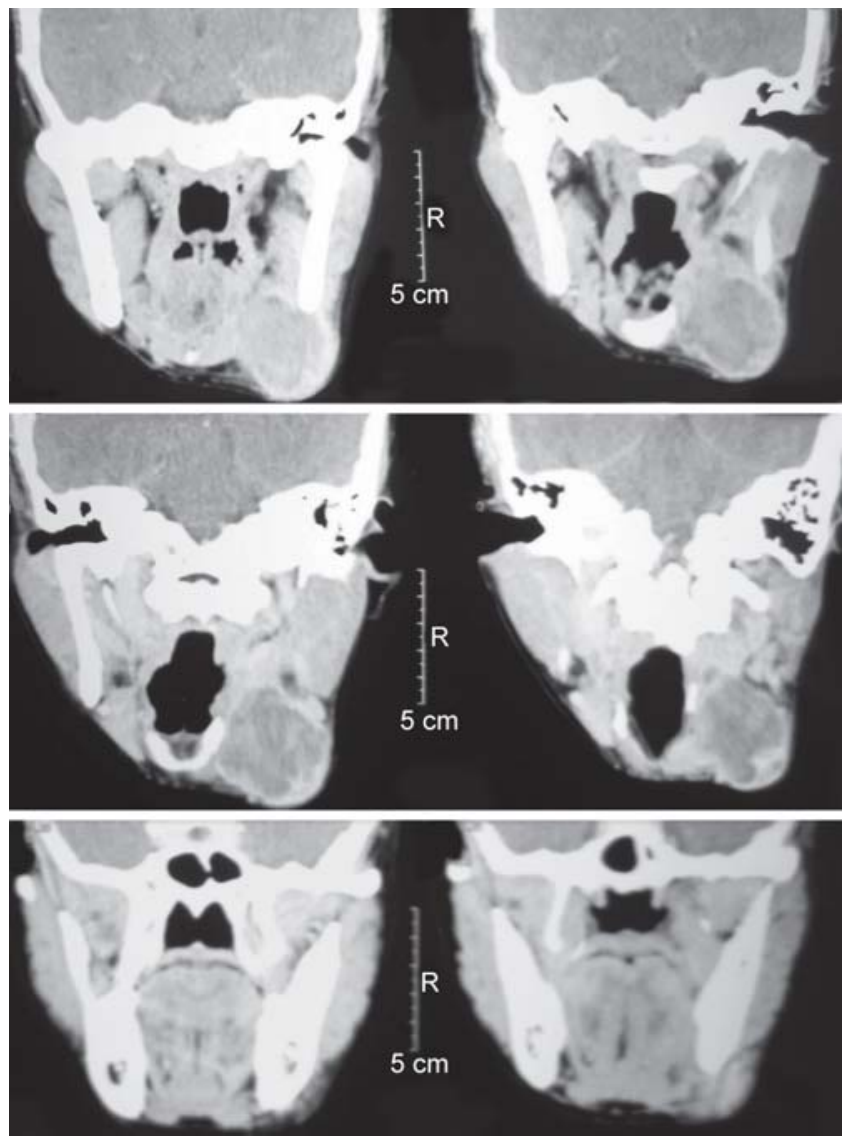

Fig. 3: Coronal CT cuts showing heterogeneous mass with no separation from the submandibular gland 
12 to $55 \%$ cases with rapid increase in size and asymptomatic in few cases only. ${ }^{13,14}$

Early stages of CXPA have a 5 years survival rates of 30 to $76 \%$ while advanced diseases have even lesser survival rates. ${ }^{7,15}$ Only $27 \%$ of patients are alive 1 year after diagnosis of recurrence or metastasis. ${ }^{7,15}$ Malignant changes in the pleomorphic adenoma includes three different types CXPA, carcinosarcoma and metastasizing pleomorphic adenoma. ${ }^{16}$ The macroscopic features suggesting malignant transformation in pleomorphic adenoma include poorly defined or infiltrative margins with presence of foci of hemorrhage and necrosis. ${ }^{17}$

A significant predictor of outcome in salivary gland carcinomas are histologic grades apart from tumor size and nodal status. ${ }^{6}$ CXPA is not automatically a high-grade tumor as is traditionally suggested and should be further qualified as to type, grade of carcinoma and extent, since intracapsular and minimally invasive CXPA behave favorably. ${ }^{6}$

Clinical literature of CXPA suggests that most common histologic subtype of the carcinomatous component being
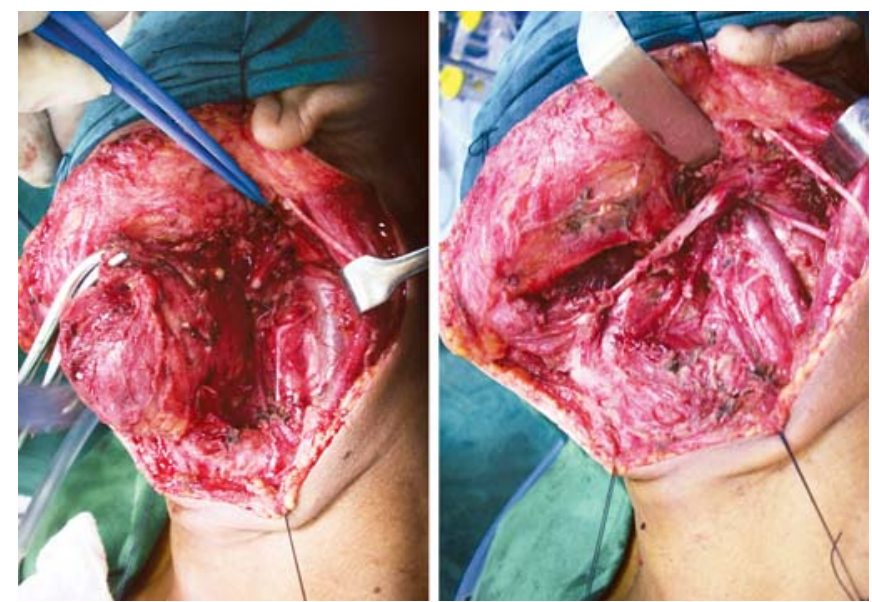

Fig. 4: Intraoperatively, the tumor being excised

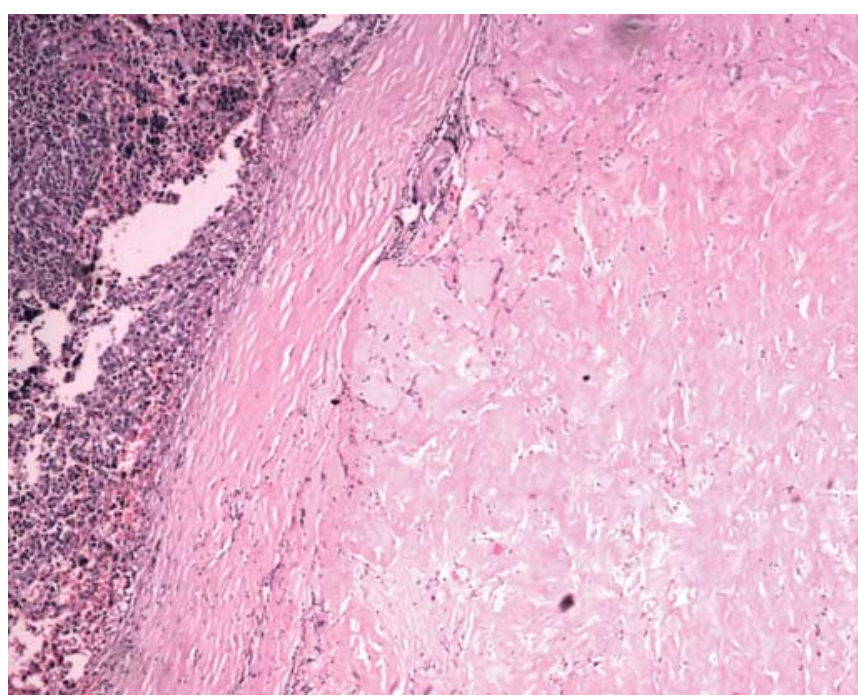

Fig. 5: Earlier pleomorphic adenoma areas with hyaline areas, with adjacent high-grade expleomorphic adenoma a high-grade adenocarcinoma, not otherwise specified (NOS) and a salivary duct carcinoma. ${ }^{16,18}$ Fifteen percent of these cancers are low grade as they are intracapsular and minimally invasive carcinoma ( $<1.5 \mathrm{~mm}$ of invasion) and should not be considered equivalent to the typical CXPA. ${ }^{6}$

Prognosis is better with intracapsular or minimally invasive tumors compared to widely invasive tumors but recurrences are also common with intracapsular and minimally invasive CXPA. ${ }^{19}$ The presence of myoepithelial carcinoma subtype increases the risk of recurrence in intracapsular and minimally invasive type of CXPA. ${ }^{19}$

Factors like vascular invasion, high mitotic rate, and histologic subtype were found to correlate with these high recurrence rates. ${ }^{19}$

Zbaren et al in their study on 24 cases of CXPA found the deep lobe to be involved in 33\%, while an overall survival rate of $76 \%$ were seen at 5 years and an recurrence rate of $25 \%$ were seen. ${ }^{20}$ Studies by Eneroth and Zetterberg support the hypothesis that risk of carcinomatous transformation increases with the age of the tumor. They also suggested the classical features of CXPA are capsule invasion, hemorrhage, necrosis alternating among themselves. ${ }^{4,21}$

Highly malignant adenocarcinoma or undifferentied carcinoma are the most frequently encountered histological types in CXPA although other types like squamous cell carcinoma, mucoepidermoid carcinoma, adenoid cystic carcinoma, papillary carcinoma and terminal duct carcinoma are also seen. ${ }^{7}$ Total parotidectomy with neck dissection is the treatment for CXPA with postoperative radiotherapy as suggested by many authors. ${ }^{22,23}$

Chen and Colab reported a rise in tumor control rates from 49 to $75 \%$ when postoperative radiotherapy was given in 63 patients with CXPA. ${ }^{22,23}$ They also noticed poor prognosis with high tumor grade, large sizes, soft tissue invasion, perineural invasion and nodal metastasis. ${ }^{22,23}$ Tortoledo et al reported a histopathologic subclassification for a study of 37 cases of CXPA where 13 were ductal, 10 undifferentiated, nine terminal duct and three myoepithelial types but two cases could not be classified due to the small size of the surgical specimen. ${ }^{24}$

LiVolsi and Perzin in their study remarked that tumor infiltration beyond the capsule is the most reliable prognostic marker and CXPA metastasizes exclusively as a carcinoma. ${ }^{25}$ Mitchell et al reported that distant metastasis are common than distant metastasis and show high affinity to bone and lung especially the vertebral column. ${ }^{26}$

Luers et al retrospectively analyzed 22 cases of CXPA, and found that 11 cases had an history of parotid mass of 1 year only and the maximum in the other 11 cases was 48 years. Five-year disease specific and overall survival was $60 \%$ and recurrence free survival after 5 years was 


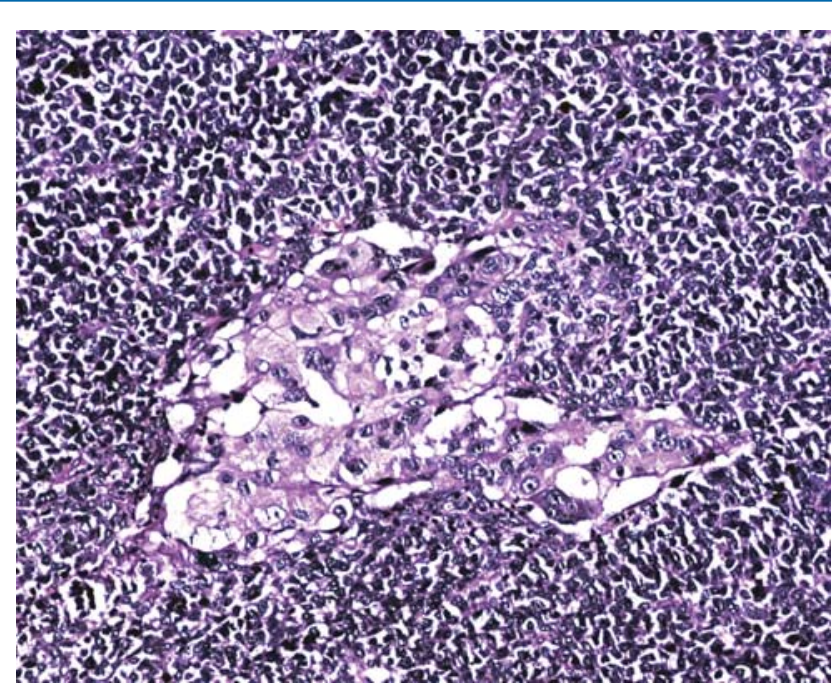

Fig. 6: Squamoid areas of mucoepidermoid carcinoma

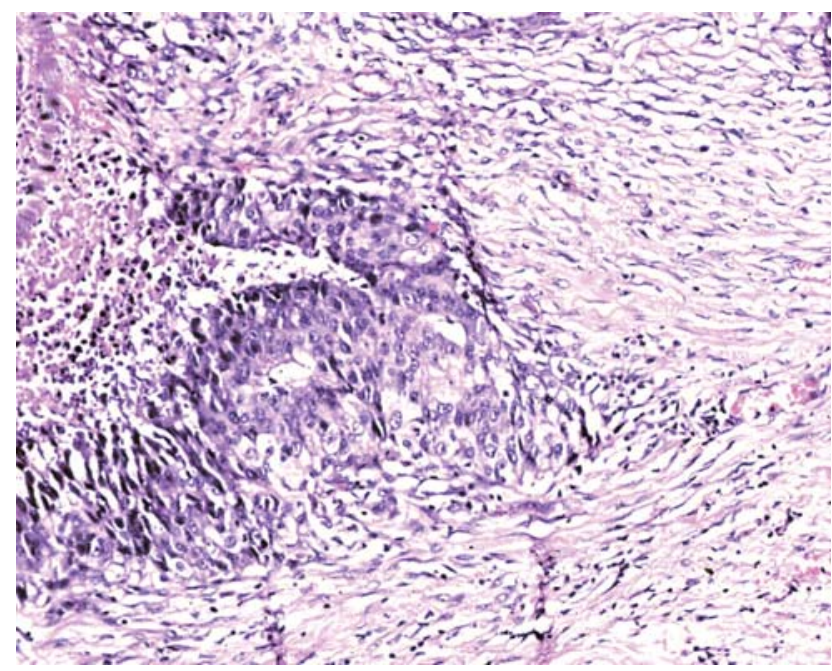

Fig. 7: Mucoepidermoid foci in between carcinoma expleomorphic features

$85 \% .{ }^{27}$ Iino et al reported a case of CXPA with regional lymph node metastasis in the left submandibular gland of a 64-year-old man. ${ }^{28}$ Gland excision and ipsilateral neck dissection was followed by radiotherapy. ${ }^{28}$ Clear cell squamous cell carcinoma was diagnosed which is rare in head neck region. ${ }^{28}$ Contralateral neck dissection was done 4 months after radiation and the patient remained disease free for 29 months. $^{28}$

To and Tsang et al reported a case of CXPA in which mucoepidermoid carcinoma arose from a previous incompletely excised pleomorphic adenoma of the submandibular gland. Wide tumor resection with modified radical neck dissection and postoperative radiotherapy gave the patient a disease free period of 3 years. ${ }^{29}$

\section{CONCLUSION}

Surgical management of pleomorphic adenomas should be accurate as it has potential for malignant transformation and the mere fact of it being benign should not mask the wide range of biologic behaviors associated with these tumors.
Surgery followed by postoperative radiation should be considered the standard of care for patients with CXPA. Histologic grading alone does not have a prognostic value in salivary gland carcinomas. CXPA should no longer be considered a specific diagnosis but a category in which the carcinoma should be typed, graded and quantitated to impart more prognostically and therapeutically relevant data.

\section{REFERENCES}

1. Heintz PW, Schmidt WA, Pommier RF, Vetto JT, DiTomasso JP. Submandibular gland carcinoma expleomorphic adenoma. Report of a case with cytologic features and diagnostic pitfalls. Acta Cytol 1998 Nov-Dec;42(6):1431-36.

2. Eveson JW, Auclair PL, Gnepp DR, et al. Tumors of the salivary glands: Introduction. In: Barnes EL, Eveson JW, Reichart P, Sidransk D, (Eds). World Health Organization classification of tumours: Pathology and genetics. Head and neck tumors. Lyon: IARC Press 2005;221-22.

3. Bell RB, Dierks EJ, Homer L, et al. Management and outcome of patients with malignant salivary gland tumors. J Oral Maxillofac Surg 2005;63(7):917-28.

4. Myers EN, Ferris RL (Eds). Salivary gland disorders. Berlin: Springer 2007.

5. Lima RA, Tavares MR, Dias FL, et al. Clinical prognostic factors in malignant parotid gland tumors. Otolaryngol Head Neck Surg 2005;133(5):702-08.

6. Seethala RR. An update on grading of salivary gland carcinomas. Head and Neck Pathol 2009;3:69-77.

7. Olsen KD, Lewis JE. Carcinoma expleomorphic adenoma: A clinic-pathologic review. Head Neck 2001;23:705-12.

8. Mag A, Cotulbea S, Marin AH, Doros C, et al. Carcinoma expleomorphic adenoma in parotid gland-case report: Journal of Experimental Medical and Surgical Research Cercetãri Experimentale and MedicoChirurgicale XVII • Nr.3/2010;205-09.

9. Cardesa A, Slootweg PJ (Eds). Pathology of the head and neck. Springer-Verlag LLC, New York 2006;5:156-58.

10. Sheedy SP, Welker KM, DeLone DR. CNS metastases of carcinoma expleomorphic adenoma of the parotid gland. Am J Neuroradiol 2006;27:1483-85.

11. Foote FW Jr, Frazell EL. Tumors of the major salivary glands. Cancer 1953;6:1065-1133.

12. Waldron CA, el Mofty SK, Gnepp DR. Tumors of the intraoral minor salivary glands: A demographic and histologic study of 426 cases. Oral Surg Oral Pathol 1988;66:323-33.

13. Beahrs $\mathrm{OH}$, Woolner LB, Kirklin JW, et al. Carcinomatous transformation of mixed tumors of the parotid gland. AMA Arch Surg 1987;75:605-13.

14. Batsakis JG. Malignant mixed tumor. Ann Otol Rhinol Laryngol 1982;91:342-43.

15. Wahlberg P, Anderson H, Biorklund A, Moller T, Perfekt R. Carcinoma of the parotid and submandibular glands-a study of survival in 2465 patients. Oral Oncol 2002;38:706-13.

16. Eveson JW. Malignant neoplasms of the salivary gland. In: Tompson LD (Ed). Head and neck pathology. Philadelphia: Churchill Livingstone 2006;321-70.

17. Gnepp DR, Brandwein-Gensler MS, El-Naggar AK, et al. Carcinoma expleomorphic adenoma. In: Barnes L, Eveson JW, Reichart P, Sidransky D (Eds). World Health Organization classification of tumours. Pathology and genetics of head and neck tumours. Lyon: IARC Press 2005;242-43. 
18. Fletcher CD. Diagnostic histopathology of tumors. London: Churchill Livingstone 2000;233-303.

19. Katabi N, Gomez D, Klimstra DS, Carlson DL, Lee N, Ghossein R. Prognostic factors of recurrence in salivary carcinoma expleomorphic adenoma, with emphasis on the carcinoma histologic subtype: A clinicopathologic study of 43 cases. Hum Pathol 2010 Jul;41(7):927-34.

20. Zbaren P, Zbaren S, Caversaccio MD. Carcinoma ex-pleomorphic adenoma: Diagnostic difficulty and outcome. OtolaryngologyHead and Neck Surgery 2008 May;138:601-05.

21. Eneroth CM, Zetterberg A. Malignancy in pleomorphic adenoma. A clinical and microspectrophotometric study. Acta Otolaryngol 1974;77:426-32.

22. Chen AM, Garcia J, Bucci MK. Recurrent pleomorphic adenoma of the parotid gland: Long-term outcome of patients treated with radiation therapy. Int J Radiat Oncol, Biol, Phys 2007 Jan;67: 138-43.

23. Stodulski D, Rzepko R, Kowalska B. Carcinoma expleomorphic adenoma of major salivary glands-a clinicopathologic rewiew. Otolaryngologia Polska 2007;61:687-93.

24. Tortoledo ME, Luna MA, Batsakis JG. Carcinomas expleomorphic adenoma and malignant mixed tumors. Histopathological Indexes. Arch Otolaryngol 1984;110(3):172-76.

25. LiVolsi VA, Perzin KH. Maligmant mixed tumors arising in salivary glands. I. Carcinomas arising in benign mixed tumors: A clinicopathologic study. Cancer 1977;39:2209-30.

26. Mitchell DA, Eveson JW, Ord RA. Polymorphous low-grade adenocarcinoma of minor salivary glands-a report of three cases. Br J Oral Maxillofac Surg 1989;27:494-500.

27. Luers JC, Wittekindt C, Streppel M. Carcinoma expleomorphic adenoma of the parotid gland. Study and implications for diagnostics and therapy. Acta Oncologica (Stockholm) 2009;48: 132-36.

28. Iino M, Yamada H, Ishikawa H, Suzuki M, Shomura E, Ide F, et al. Carcinoma ex-pleomorphic adenoma of the submandibular gland: Report of a case with an unusual malignant component of clear cell squamous cell carcinoma: Oral Surg Oral Med Oral Patho, Oral Radiol Endodontol 2008 Aug;106(2):30-34.

29. To EW, Tsang WM, Tse GM. Mucoepidermoid carcinoma expleomorphic adenoma of the submandibular gland. Am J Otolaryngol 2003 Jul-Aug;24(4):253-57.

\section{ABOUT THE AUTHORS}

\section{Sudhir M Naik (Corresponding Author)}

Fellow, Department of Head and Neck Oncosurgery, Kidwai Memorial Institute of Oncology, Bengaluru, Karnataka, India e-mail: sud223@gmail.com

\section{Ashok M Shenoy}

Professor and Head, Department of Head and Neck Oncosurgery Kidwai Memorial Institute of Oncology, Bengaluru, Karnataka, India

\section{Purshottam Chavan}

Assistant Professor, Department of Head and Neck Oncosurgery Kidwai Memorial Institute of Oncology, Bengaluru, Karnataka, India

\section{Rajshekar Halkud}

Associate Professor, Department of Head and Neck Oncosurgery Kidwai Memorial Institute of Oncology, Bengaluru, Karnataka, India

\section{Siddharth Biswas}

Professor, Department of Pathology, Kidwai Memorial Institute of Oncology, Bengaluru, Karnataka, India

\section{Mahesh Kalloli}

Senior Resident, Department of Surgical Oncology, Kidwai Memorial Institute of Oncology, Bengaluru, Karnataka, India

\section{Sumit Gupta}

Fellow, Department of Head and Neck Oncosurgery, Kidwai Memorial Institute of Oncology, Bengaluru, Karnataka, India

\section{Akshay Kudpaje}

Fellow, Department of Head and Neck Oncology, Kidwai Memorial Institute of Oncology, Bengaluru, Karnataka, India 